\title{
Mechaniczne powikłania zawału serca
}

\author{
Mechanical compliations of myocardial infarction
}

\author{
Mateusz Machura ${ }^{1}$, Bartosz Hudzik ${ }^{1,2}$, Mariusz Gąsior ${ }^{1}$ \\ ${ }^{1}$ III Katedra i Oddział Kliniczny Kardiologii Śląskiego Centrum Chorób Serca w Zabrzu, Wydział Lekarski z Oddziałem Lekarsko- \\ -Dentystycznym w Zabrzu, Śląski Uniwersytet Medyczny w Katowicach \\ ${ }^{2}$ Zakład Profilaktyki Chorób Żywieniowozależnych Wydziału Zdrowia Publicznego w Bytomiu, \\ Śląski Uniwersytet Medyczny w Katowicach
}

\section{Streszczenie}

Choroba niedokrwienna serca od lat pozostaje wiodącą przyczyną zgonów w krajach rozwiniętych. Powikłania mechaniczne zawału serca występują rzadko, jednak są obarczone bardzo wysoką śmiertelnością. W artykule pokrótce przedstawiono epidemiologię, obraz kliniczny, diagnostykę i leczenie najczęstszych z nich: pęknięcia wolnej ściany lewej komory, pęknięcia przegrody międzykomorowej, ostrej niedomykalności zastawki mitralnej w przebiegu pęknięcia mięśnia brodawkowatego.

Słowa kluczowe: zawał serca, powikłania mechaniczne, pęknięcie wolnej ściany lewej komory, pęknięcie przegrody międzykomorowej, ostra niedomykalność zastawki mitralnej, pęknięcie mięśnia brodawkowatego

Folia Cardiologica 2017; 12, 6: 565-569

\section{Wstęp}

Mimo coraz głębszej wiedzy na temat etiologii oraz stale rozwijających się metod leczenia, choroby układu sercowo-naczyniowego stanowią główną przyczynę umieralności zarówno w Polsce, jak i w całej Unii Europejskiej [1]. Dynamiczny rozwój kardiologii interwencyjnej poprawił rokowanie chorych z ostrymi zespołami wieńcowymi (ACS, acute coronary syndrome), jednak nadal za największy odsetek zgonów z przyczyn kardiologicznych odpowiada choroba niedokrwienna serca. Każdego roku w Polsce notuje się przeszło 140 tys. przypadków ACS, przy czym $60 \%$ stanowią pacjenci z zawałem serca (MI, myocardial infarction). Śmiertelność wewnątrzszpitalna wynosi 4,9\% w przypadku pacjentów z zawałem serca bez uniesienia odcinka ST (NSTEMI, non-ST-elevation myocardial infarction) oraz 5,9\% wśród chorych z zawałem serca $z$ uniesieniem odcinka ST (STEMI, ST-elevation myocardial infarction) [2]. I choć w dobie powszechnego dostępu do leczenia inwazyjnego powikłania mechaniczne występują w niespełna 1\% przypadków MI, to - według różnych danych - odpowiadają za 8-18\% wszystkich zgonów w trakcie hospitalizacji $[3,4]$.

\section{Pęknięcie wolnej ściany lewej komory}

Najczęstszym mechanicznym powikłaniem MI jest pęknięcie wolnej ściany lewej komory (FWR, free wall rupture), które występuje u 0,5\% chorych z MI [5], a w badaniach pośmiertnych można je zaobserwować aż u 18\% zmarłych z powodu MI. Zidentyfikowano niezależne czynniki zwiększające ryzyko wystąpienia tego powikłania: płeć żeńską, starszy wiek, dłuższy czas od wystąpienia objawów podmiotowych do wykonania przezskórnej angioplastyki wieńcowej [4], brak wcześniejszego wywiadu w kierunku przebytego MI [6], przewlekłą chorobę nerek [7]. Co ciekawe, częstość występowania FWR oraz śmiertelność nie zmieniły się przez dwie ostatnie dekady [7].

Adres do korespondencji: lek. Mateusz Machura, III Katedra i Oddział Kliniczny Kardiologii, Śląskie Centrum Chorób Serca w Zabrzu, Wydział Lekarski z Oddziałem Lekarsko-Dentystycznym w Zabrzu, Śląski Uniwersytet Medyczny w Katowicach, ul. Marii Curie-Skłodowskiej 9, 41-800 Zabrze, e-mail: machura.mateusz@gmail.com 
Niektórzy autorzy wyróżniają trzy typy FWR, zależnie od tempa rozwoju tego powikłania - ostry, podostry i przewlekły. W typie ostrym występują gwałtownie narastająca tamponada, hipotensja i zatrzymanie akcji serca w mechanizmie rozkojarzenia elektromechanicznego, prowadzące do zgonu w ciągu kilku minut. W typie podostrym dynamika zachodzących procesów patofizjologicznych jest nieco mniejsza, tak że możliwe jest podjęcie próby leczenia chirurgicznego. W przypadku pęknięcia przewlekłego ilość wynaczynionej krwi jest stosunkowo niewielka i dochodzi do powstania tętniaka rzekomego, którego ściany stanowią blaszki osierdzia i uformowane skrzepliny [8].

U nieco ponad połowy chorych do FWR dochodzi w czasie 24 godzin od wystąpienia bólu stenokardialnego [5]. Objawy podmiotowe i przedmiotowe są niecharakterystyczne; chorzy skarżą się na ból zamostkowy, może wystąpić omdlenie wskutek nagłego spadku ciśnienia tętniczego, w przypadkach o przebiegu podostrym część pacjentów skarży się na nudności [9]. W badaniu przedmiotowym warto pamiętać o łączonej z tamponadą osierdziową tak zwanej triadzie Becka, na którą składają się: nadmierne wypełnienie żył szyjnych, stłumienie tonów serca, hipotensja. W zapisie elektrokardiograficznym (EKG) na ryzyko wystąpienia FWR mogą wskazywać utrzymujące się po reperfuzji uniesienia odcinka ST [10].

Podstawowym badaniem służącym rozpoznaniu FWR jest echokardiografia przezklatkowa [11]. W badaniu echokardiograficznym za obecnością FWR przemawiają: obecność ponad $5 \mathrm{~mm}$ płynu w worku osierdziowym, zapadanie się jam serca, poszerzenie żyły głównej dolnej, uwidocznienie płynu hiperechogenicznego wokół serca. Dokładne zlokalizowanie przecieku przez szczelinę nie zawsze jest możliwe - pomóc może wykorzystanie obrazowania 3D [12] bądź badanie z użyciem kontrastu [13]. Szczelinę pęknięcia uwidacznia się najłatwiej w wentrykulografii [14], tomografii komputerowej [15] i rezonansie magnetycznym, o ile stan chorego pozwala na wykonanie tych badań.

Postępowanie przedoperacyjne polega na utrzymaniu hemodynamicznie wydolnego rytmu serca do czasu przeprowadzenia zabiegu kardiochirurgicznego. W tym celu stosuje się uzupełnianie utraconej objętości krwi krążącej roztworami koloidów i krystaloidów, wlew amin presyjnych, kontrapulsację wewnątrzaortalną i masaż zewnętrzny serca. Pomocne może być wykonanie perikardiocentezy w celu zwiększenia rzutu serca [11], ponadto uzyskanie aspiratu krwawego płynu u pacjentów w ostrej fazie Ml z dużym prawdopodobieństwem świadczy o obecności FWR. Należy jednak mieć na uwadze, że drenaż znacznej ilości krwi, poprzez zwiększenie gradientu przez szczelinę, może spowodować powiększenie jej rozmiarów, a zwiększona w ten sposób utrata krwi może sprowokować lub nasilić objawy wstrząsu.

Podejmuje się próby leczenia zachowawczego u chorych dobrze odpowiadających na leczenie objawowe, z elektywną operacją w przypadku nagłej dekompensacji [8]. Opisywano również metode podawania kleju fibrynowego do worka osierdziowego z dobrym efektem [16]. Nadal jednak leczenie definitywne polega na chirurgicznym zamknięciu szczeliny oraz pokryciu jej łatą z osierdzia lub teflonu przy użyciu szwów lub kleju cyjanoakrylowego [17]. Jeśli stwierdzono obecność zwężeń lub niedrożności tętnic nasierdziowych, które nie zostały zaopatrzone metodą przezskórnej interwencji wieńcowej (PCl, percutaneous coronary intervention), to jednoczasowo wykonuje się pomostowanie aortalno-wieńcowe.

Rokowanie u chorych, u których doszło do FWR, jest niepomyślne - tylko 37\% przeżywa 30 dni od momentu rozpoznania [5].

\section{Pęknięcie przegrody międzykomorowej}

Częstość występowania pęknięcia przegrody międzykomorowej (VSR, ventricular septal rupture) po MI ocenia się na $0,2 \%[3,18]$. Na występowanie tego powikłania niezależnie wpływają starszy wiek pacjenta, płeć żeńska, niepalenie tytoniu oraz lokalizacja zawału w obrębie ściany przedniej. Aż u $60 \%$ chorych z VSR w koronarografii stwierdza się istotne zmiany w gałęzi przedniej zstępującej, a zwykle również całkowitą niedrożność zajętego naczynia [18].

Ze względu na przebieg szczeliny można wyróżnić pęknięcia proste, w przypadku których wrota powstałego kanału znajdują się na tym samym poziomie mięśnia przegrody w obu komorach oraz pęknięcia złożone o bardziej krętym przebiegu [19]. W większości przypadków do powstania VSR dochodzi 24 godziny po wystąpieniu pierwszych objawów MI [5]. Objawy podmiotowe VSR to ból w klatce piersiowej i ogólne pogorszenie stanu klinicznego; u 71\% chorych występuje wstrząs kardiogenny [20]. W badaniu przedmiotowym uwage zwraca głośny szmer holosystoliczny słyszalny wzdłuż lewego brzegu mostka [21]. W zapisie EKG może się pojawić blok przedsionkowo-komorowy III stopnia lub bloki odnóg pęczka Hisa.

Podstawowym badaniem do weryfikacji podejrzenia VSR jest echokardiografia doplerowska kodowana kolorem [21]. To stosunkowo proste, szybkie i łatwo dostępne badanie pozwala zlokalizować miejsce przecieku, oszacować jego istotność hemodynamiczną oraz wykluczyć inne powikłania mechaniczne. Tomografia komputerowa z kolei umożliwia dokładniejsze zobrazowanie przebiegu szczeliny pęknięcia [16], jednak bez oceny przepływu krwi przez ubytek.

Cewnikowanie serca z pomiarem ciśnień, wentrykulografią oraz oksymetrią z obliczaniem stosunku przepływu płucnego do ciśnieniowego są warte rozważenia w przypadku założonego dostępu naczyniowego [21]. W innych wypadkach mogą niepotrzebnie wydłużać czas do podjęcia leczenia chirurgicznego, gdyż nie są niezbędne w dokonaniu rozpoznania i kwalifikowaniu do operacji. Celowe jest 
natomiast stałe monitorowanie parametrów hemodynamicznych za pomocą cewnika Swana-Ganza. Pozwala to na szybkie rozpoznanie nagłej dekompensacji, na przykład w wyniku powiększenia szczeliny, wymagającej natychmiastowej interwencji kardiochirurgicznej.

Głównym zadaniem leczenia objawowego jest ograniczenie przecieku przez ubytek w przegrodzie międzykomorowej. W tym celu należy dążyć do zmniejszenia obciążenia następczego lewej komory, podając leki o działaniu wazodylatacyjnym, takie jak azotany czy inhibitory fosfodiesterazy 3. W przypadku niedostatecznej perfuzji narządowej konieczne staje się zastosowanie leków o działaniu inotropowym i mechaniczne wspomaganie pracy serca, z użyciem kontrapulsacji wewnątrzaortalnej lub pomp mechanicznych. Ponieważ operacja we wczesnym okresie pozawałowym wiąże się ze znacznie gorszym rokowaniem [22], to podejmowane są próby wspomagania układu krążenia metodą pozaustrojowego utlenowania krwi (ECMO, extracorporeal membrane oxygenation) [23] czy urządzeń typu Impella [24] jako pomostu przed odroczonym zabiegiem kardiochirurgicznym.

Leczenie definitywne polega na wycięciu martwiczych tkanek oraz zamknięciu ubytku w przegrodzie łatą z osierdzia, z następczym wszyciem pomostów w przypadku obecności istotnych zwężeń tętnic wieńcowych. Ze względu na stosowany dostęp operacyjny, wymagający całkowitego wyłączenia funkcji lewej komory, zabieg przeprowadza się z wykorzystaniem krążenia pozaustrojowego.

Podejmowane są również próby przeznaczyniowego zamykania ubytku przy pomocy okludera Amplatza [25], wykorzystywanego do korekcji wrodzonych wad serca pod postacią ubytku przegrody międzykomorowej (VSD, ventricular septal defect). Jest to jednak metoda zarezerwowana dla ubytków o prostym przebiegu i odpowiedniej lokalizacji [26]. Ponadto pozostają obawy związane z niebezpieczeństwem rozerwania przez wprowadzony okluder otaczających go martwiczych tkanek, zwłaszcza jeśli zabieg zostanie przeprowadzony we wczesnym okresie MI [27].

Śmiertelność 30-dniowa wśród pacjentów z VSR wynosi $62 \%$ i jest znacząco wyższa u chorych leczonych zachowawczo w stosunku do leczonych operacyjnie - 94\% w porównaniu z 47\% [18].

\section{Ostra niedomykalność zastawki mitralnej}

Ostra niedomykalność zastawki mitralnej (AMR, acute mitral regurgitation) w przebiegu pęknięcia mięśnia brodawkowatego (PMR, papillary muscle rupture) stanowi powikłanie 0,26\% MI i typowo występuje w 2. dobie zawału [5]. Zdecydowanie częściej współistnieje w przebiegu ostrego niedokrwienia ściany dolnej, co wiąże się z unaczynieniem mięśni brodawkowatych. Mięsień tylno-przyśrodkowy jest zwykle unaczyniony przez gałąź tylną zstępującą, co predysponuje do szybkiego rozwoju niedokrwienia i martwicy mięśnia w przypadku zamknięcia tego naczynia. Z kolei mięsień przednio-boczny jest zaopatrywany zarówno przez gałąź tępego brzegu, odchodzącą od gałęzi okalającej, jak i gałąź diagonalną, stanowiącą odnogę gałęzi przedniej zstępującej, co zapewnia utrzymanie zaopatrzenia nawet w przypadku zamknięcia jednego z głównych naczyń [28].

Należy zaznaczyć, że nie każdy przypadek niedomykalności zastawki mitralnej po MI jest związany z PMR. U wielu chorych dysfunkcja zastawki jest wynikiem zmienionej w wyniku niedokrwienia geometrii lewej komory [29], jednak w takich przypadkach przebieg kliniczny jest mniej dramatyczny. Objawy sugerujące PMR w przebiegu MI to nagle pojawiający się obrzęk płuc i hipotensja, do wstrząsu kardiogennego włącznie. W badaniu przedmiotowym daje się ponadto wysłuchać szmer holosystoliczny nad koniuszkiem, choć w przypadku dużego spadku ciśnienia w lewej komorze i jego wzrostu w lewym przedsionku szmer może być niesłyszalny.

Podobnie jak w pozostałych powikłaniach mechanicznych podstawowym narzędziem diagnostycznym jest echokardiografia. Poza falą zwrotną do lewego przedsionka można również uwidocznić fragment pękniętego mięśnia, który, połączony za pomocą nici ścięgnistych z aparatem zastawkowym, przemieszcza się w czasie skurczu z lewej komory do lewego przedsionka. W przypadkach niejasnych na lepsze zobrazowanie zastawki mitralnej pozwala zastosowanie echokardiografii przezprzełykowej [30].

W celu weryfikacji rozpoznania oraz różnicowania z VSR przydatne pozostają metody inwazyjne - cewnikowanie prawego serca i wentrykulografia. Spośród pozostałych badań dodatkowych warto wymienić zdjęcie rentgenowskie klatki piersiowej, na którym można zobrazować charakterystyczny dla obrzęku płuc obraz „skrzydeł motyla”. W zapisie EKG nie pojawią się nieprawidłowości poza tymi wskazującymi na ostre niedokrwienie, należy jednak pamiętać o trudnościach diagnostycznych związanych z rozpoznawaniem zawału ściany tylnej.

W okresie przedoperacyjnym, w celu poprawy rzutu serca i zmniejszenia obrzęku płuc, należy zastosować kontrapulsacje wewnątrzaortalną [31]. U chorych z prawidłowym ciśnieniem tętniczym zwiększenie perfuzji narządowej daje się osiągnąć poprzez podaż leków wazodylatacyjnych, w przypadku nasilonej hipotensji konieczne może być zastosowanie leków o działaniu inotropowym.

We wszystkich przypadkach PMR należy przeprowadzić pilną operację kardiochirurgiczną. Najczęściej implantuje się zastawkę mechaniczną, choć w przypadku odpowiedniej morfologii z sukcesem można przeprowadzać zabiegi naprawcze. Na poprawę rokowania wpływa również przeprowadzenie równoczasowo pełnej, chirurgicznej rewaskularyzacji wieńcowej. Spośród wszystkich chorych z powikłaniami mechanicznymi MI to właśnie pacjenci z PMR odnoszą największe korzyści z leczenia operacyjnego 
- śmiertelność 30-dniowa u osób poddanych leczeniu chirurgicznemu wynosi $24 \%$ [28].

\section{Podsumowanie}

Postępy w diagnostyce i leczeniu ACS pozwoliły na znamienne ograniczenie liczby powikłań mechanicznych [29], nadal jednak są to zdarzenia obarczone znaczną śmiertelnością. Mimo wysokiego odsetka zgonów w okresie okołozabiegowym leczenie operacyjne pozostaje podstawową metodą pozwalającą na zwiększenie szans na przeżycie. Kluczowe dla poprawy rokowania wydają się czujna obserwacja, szybka diagnoza doświadczonego echokardiografisty, sprawne wdrożenie intensywnego leczenia objawowego i gotowość zespołu kardiochirurgicznego do przeprowadzenia pilnej operacji.

\section{Konflikt interesów}

Autorzy deklarują brak konfliktu interesów.

\section{Abstract}

Ischemic heart disease has been the leading cause of death in developed countries for years. Mechanical complications of myocardial infarction are rare, but they have a very high mortality rate. The present paper outlines the epidemiology, clinical presentation, diagnosis and treatment of the most common of them: left ventricular free wall rupture, ventricular septal rupture, and acute mitral regurgitation in the course of papillary muscle rupture.

Key words: myocardial infarction, mechanical complications, free wall rupture, ventricular septal rupture, acute mitral regurgitation, papillary muscle rupture

Folia Cardiologica 2017; 12, 6: 565-569

\section{Piśmiennictwo}

1. Cierniak-Piotrowska M, Marciniak G, Stańczak J. Statystyka zgonów i zachorowalności z powodu chorób układu krążenia. In: Zachorowalność i umieralność na choroby układu krążenia a sytuacja demograficzna Polski. Rządowa Rada Ludnościowa, Warszawa 2015.

2. Poloński L, Gasior M, Gierlotka M, et al. Polish Registry of Acute Coronary Syndromes (PL-ACS). Characteristics, treatments and outcomes of patients with acute coronary syndromes in Poland. Kardiol Pol. 2007; 65(8): 861-72; discussion 873, indexed in Pubmed: 17853315.

3. Hawranek M, Gąsior M, Nożyński J, et al. Przyczyny zgonów chorych z zawałem serca w dobie leczenia reperfuzyjnego. Folia Cardiol. 2004; 11(4): 239-245.

4. Markowicz-Pawlus E, Nozyński J, Sedkowska A, et al. Cardiac rupture risk estimation in patients with acute myocardial infarction treated with percutaneous coronary intervention. Cardiol J. 2007; 14(6): 538-543, indexed in Pubmed: 18651519.

5. French JK, Hellkamp AS, Armstrong PW, et al. Mechanical complications after percutaneous coronary intervention in ST-elevation myocardial infarction (from APEX-AMI). Am J Cardiol. 2010; 105(1): 59-63, doi: 10.1016/j.amjcard.2009.08.653, indexed in Pubmed: 20102891.

6. Markowicz-Pawlus E, Nożyński J, Duszańska A, et al. The impact of a previous history of ischaemic episodes on the occurrence of left ventricular free wall rupture in the setting of myocardial infarction. Kardiol Pol. 2012; 70(7): 713-717, indexed in Pubmed: 22825948.

7. Moreyra AE, Huang MS, Wilson AC, et al. MIDAS Study Group (MIDAS 13). Trends in incidence and mortality rates of ventricular septal rupture during acute myocardial infarction. Am J Cardiol. 2010; 106(8):
1095-1100, doi: 10.1016/j.amjcard.2010.06.013, indexed in Pubmed: 20920645.

8. Figueras J, Cortadellas J, Soler-Soler J. Left ventricular free wall rupture: clinical presentation and management. Heart. 2000; 83(5): 499-504, doi: 10.1136/heart.83.5.499, indexed in Pubmed: 10768896.

9. López-Sendón J, González A, López de Sá E, et al. Diagnosis of subacute ventricular wall rupture after acute myocardial infarction: sensitivity and specificity of clinical, hemodynamic and echocardiographic criteria. J Am Coll Cardiol. 1992; 19(6): 1145-1153, doi: 10.1016/0735-1097(92)90315-e, indexed in Pubmed: 1564213.

10. Wehrens XH, Doevendans PA, Widdershoven JW, et al. Usefulness of sinus tachycardia and ST-segment elevation in V(5) to identify impending left ventricular free wall rupture in inferior wall myocardial infarction. Am J Cardiol. 2001; 88(4): 414-417, indexed in Pubmed: 11545766.

11. Okabe T, Julien HM, Kaliyadan AG, et al. Prompt recognition of left ventricular free-wall rupture aided by the use of contrast echocardiography. Tex Heart Inst J. 2015; 42(5): 474-478, doi: 10.14503/ /THIJ-14-4447, indexed in Pubmed: 26504446.

12. Avsar S, Keskin M, Velibey $\mathrm{Y}$, et al. Incremental utility of real time three-dimensional transthoracic echocardiography for the assessment of left ventricular free wall rupture location, orifice geometry, and complex intracardiac flow. Echocardiography. 2015; 32(11): 1738-1741, doi: 10.1111/echo.13013, indexed in Pubmed: 26257391.

13. Liu S, Glavinovic T, Tam JW. Early diagnosis and management of myocardial rupture. Can J Cardiol. 2015; 31(1): 88-90, doi: 10.1016/j. cjca.2014.09.026, indexed in Pubmed: 25547556. 
14. Reddy YNV, Al-Hijji M, Best PJ, et al. Diagnosis of free-wall rupture by left ventricular angiogram after inferior st-segment-elevation myocardial infarction. Circulation. 2015; 132(5): e31-e33, doi: 10.1161/ /CIRCULATIONAHA.115.015951, indexed in Pubmed: 26240267.

15. Yamada H, Sakurai A, Higurashi A, et al. Cardiac CT for intraseptal pseudoaneurysm: impending double rupture of ventricular septum and left ventricular free wall. BMJ Case Rep. 2015; 2015, doi: 10.1136/bcr-2014-207352, indexed in Pubmed: 25628320.

16. Terashima M, Fujiwara S, Yaginuma Gy, et al. Outcome of percutaneous intrapericardial fibrin-glue injection therapy for left ventricular free wall rupture secondary to acute myocardial infarction. Am J Cardiol. 2008; 101(4): 419-421, doi: 10.1016/j.amjcard.2007.09.086, indexed in Pubmed: 18312750.

17. Nasir A, Gouda M, Khan A, et al. Is it ever possible to treat left ventricular free wall rupture conservatively? Interact Cardiovasc Thorac Surg. 2014; 19(3): 488-493, doi: 10.1093/icvts/ivu140, indexed in Pubmed: 24961578.

18. Crenshaw BS, Granger CB, Birnbaum Y, et al. Risk factors, angiographic patterns, and outcomes in patients with ventricular septal defect complicating acute myocardial infarction. Circulation. 2000; 101(1): 27-32, indexed in Pubmed: 10618300.

19. Edwards BS, Edwards WD, Edwards JE. Ventricular septal rupture complicating acute myocardial infarction: identification of simple and complex types in 53 autopsied hearts. Am J Cardiol. 1984; 54(10): 1201-1205, doi: 10.1016/s0002-9149(84)80067-3, indexed in Pubmed: 6507290.

20. Cinq-Mars A, Voisine P, Dagenais F, et al. Risk factors of mortality after surgical correction of ventricular septal defect following myocardial infarction: retrospective analysis and review of the literature. Int J Cardiol. 2016; 206: 27-36, doi: 10.1016/j.ijcard.2015.12.011, indexed in Pubmed: 26773765.

21. Jones BM, Kapadia SR, Smedira NG, et al. Ventricular septal rupture complicating acute myocardial infarction: a contemporary review. Eur Heart J. 2014; 35(31): 2060-2068, doi: 10.1093/eurheartj/ehu248, indexed in Pubmed: 24970335.

22. Arnaoutakis GJ, Zhao Y, George TJ, et al. Surgical repair of ventricular septal defect after myocardial infarction: outcomes from the Society of Thoracic Surgeons National Database. Ann Thorac Surg. 2012; 94(2): 436-43; discussion 443, doi: 10.1016/j.athoracsur.2012.04.020, indexed in Pubmed: 22626761.

23. Neragi-Miandoab S, Michler RE, Goldstein D, et al. Extracorporeal membrane oxygenation as a temporizing approach in a patient with shock, myocardial infarct, and a large ventricle septal defect; successful repair after six days. J Card Surg. 2013; 28(2): 193-195, doi: 10.1111/jocs.12070, indexed in Pubmed: 23350887.
24. La Torre MW, Centofanti P, Attisani M, et al. Posterior ventricular septal defect in presence of cardiogenic shock: early implantation of the impella recover LP 5.0 as a bridge to surgery. Tex Heart Inst J. 2011; 38(1): 42-49, indexed in Pubmed: 21423467.

25. Holzer R, Balzer D, Amin Z, et al. Transcatheter closure of postinfarction ventricular septal defects using the new Amplatzer muscular VSD occluder: Results of a U.S. Registry. Catheter Cardiovasc Interv. 2004; 61(2): 196-201, doi: 10.1002/ccd.10784, indexed in Pubmed: 14755811.

26. Schlotter F, de Waha S, Eitel I, et al. Interventional post-myocardial infarction ventricular septal defect closure: a systematic review of current evidence. Eurolntervention. 2016; 12(1): 94-102, doi: 10.4244/ /EIJV12I1A17, indexed in Pubmed: 27173869.

27. Bialkowski J, Szkutnik M, Kusa J, et al. [Transcatheter closure of postinfarction ventricular septal defects using Amplatzer devices]. Rev Esp Cardiol. 2007; 60(5): 548-551, doi: 10.1016/s1885-5857(07)60197-2, indexed in Pubmed: 17535768.

28. Chevalier P, Burri H, Fahrat F, et al. Perioperative outcome and long-term survival of surgery for acute post-infarction mitral regurgitation. Eur J Cardiothorac Surg. 2004; 26(2): 330-335, doi: 10.1016/j. ejcts.2004.04.027, indexed in Pubmed: 15296892.

29. Gueret P, Khalife K, Jobic Y, et al. Study Investigators. Echocardiographic assessment of the incidence of mechanical complications during the early phase of myocardial infarction in the reperfusion era: a French multicentre prospective registry. Arch Cardiovasc Dis. 2008; 101(1): 41-47, doi: 10.1016/s1875-2136(08)70254-7, indexed in Pubmed: 18391872.

30. Enriquez-Sarano M, Freeman WK, Tribouilloy CM, et al. Functional anatomy of mitral regurgitation: accuracy and outcome implications of transesophageal echocardiography. J Am Coll Cardiol. 1999; 34(4): 1129-1136, doi: 10.1016/s0735-1097(99)00314-9, indexed in Pubmed: 10520802.

31. Rihal CS, Naidu SS, Givertz MM, et al. Society for Cardiovascular Angiography and Interventions (SCAI), Heart Failure Society of America (HFSA), Society for Thoracic Surgeons (STS), American Heart Association (AHA), American College of Cardiology (ACC). 2015 SCAl/ACC/ /HFSA/STS Clinical Expert Consensus Statement on the use of percutaneous mechanical circulatory support devices in cardiovascular care: endorsed by the American Heart Assocation, the Cardiological Society of India, and Sociedad Latino Americana de Cardiologia Intervencion; Affirmation of Value by the Canadian Association of Interventional Cardiology-Association Canadienne de Cardiologie d'intervention. J Am Coll Cardiol. 2015; 65(19): 7-26, doi: 10.1016/j. jacc.2015.03.036, indexed in Pubmed: 25861963. 